\title{
Driving Behaviors: Models and Challenges for Non-Lane Based Mixed Traffic
}

\author{
Gowri Asaithambi $^{1} \cdot$ Venkatesan Kanagaraj $^{2} \cdot$ Tomer Toledo $^{3}$
}

Received: 1 December 2015/Accepted: 11 August 2016/Published online: 24 August 2016

(C) Springer International Publishing Switzerland 2016

\begin{abstract}
Most published microscopic driving behavior models, such as car following and lane changing, were developed for homogeneous and lane-based settings. In the emerging and developing world, traffic is characterized by a wide mix of vehicle types (e.g., motorized and non-motorized, two, three and four wheelers) that differ substantially in their dimensions, performance capabilities and driver behavior and by a lack of lane discipline. This paper presents a review of current driving behavior models in the context of mixed traffic, discusses their limitations and the data and modeling challenges that need to be met in order to extend and improve their fidelity. The models discussed include those for longitudinal and lateral movements and gap acceptance. The review points out some of the limitations of current models. A main limitation of current models is that they have not explicitly considered the wider range of situations that drivers in mixed traffic may face compared to drivers in homogeneous lane-based traffic, and the strategies that they may choose in order to tackle these situations. In longitudinal movement, for example,
\end{abstract}

Gowri Asaithambi

gowri_iitm@yahoo.co.in

Venkatesan Kanagaraj

vkanagaraj.iitm@gmail.com

Tomer Toledo

toledo@technion.ac.il

1 Department of Civil Engineering, National Institute of Technology Karnataka, Surathkal, Mangalore, India

2 Institute of Transport and Economics, Technical University, Dresden, Germany

3 Faculty of Civil and Environmental Engineering, Transportation Research Institute, Technion-Israel Institute of Technology, Haifa 32000, Israel such strategies include not only strict following, but also staggered following, following between two vehicles and squeezing. Furthermore, due to limited availability of trajectory data in mixed traffic, most of the models are not estimated rigorously. The outline of modeling framework for integrated driver behavior was discussed finally.

Keywords Mixed traffic - Longitudinal movement models - Lateral movement models - Trajectory data . Model calibration and validation

\section{Introduction}

The rapid economic growth of developing and emerging countries has generated an increase in travel demand, overwhelming the limited transportation infrastructure. A useful indicator of that trend is the total number of motorized vehicles, which has increased from 1981 to 2012 from 5 million to 159 million in India and from 5.5 million to 221 million in China [1, 2]. In both countries, the problem of increased motorization is compounded by an inadequate road infrastructure, unsafe vehicles and driving behavior, sharing of roads by motorized and non-motorized modes, overcrowding of vehicles, and inadequate traffic signals, signs, and traffic management (Pucher et al. [3]). These problems lead to high levels of congestion, traffic deaths and injuries and environmental pollution. In Kolkata (India), for example, the average speed during peak hours in the Central Business District (CBD) area is as low as $10 \mathrm{~km} / \mathrm{h}$ (Singh [4]). In China, the Beijing-Tibet Expressway experienced the world's worst traffic jam ever, as traffic congestion stretched more than $100 \mathrm{~km}$ from August 14 to 26, 2010 (Hickman [5]). In road related crashes, fatality rates in china and India are 22 and 17 per 100,000 
inhabitants, respectively which is higher compared to developed countries, 5 in the United Kingdom and 6 in Germany (Sivak and Schoettle [6]). In 2010, the Indian cities Chennai, Delhi, Mumbai and Kolkata, average annual particulate matter PM10 were measured at 55, 286, 97 and 136, respectively. This is 2.75 or higher times the WHO guideline (average annual particulate matter is 20 micrograms per cubic meter) indicating a truly alarming public health hazard [7].

In order to reduce congestion, the performance of the road system has to be improved through building new infrastructure and through improved operations of the existing infrastructure with efficient traffic control and management strategies. Design of useful traffic control and management measures is difficult and requires testing with various designs. In most cases, it is not practically feasible to carry out field tests of these designs. Microscopic simulation tools are commonly used to test different traffic management strategies because they mimic the driver behavior explicitly and in detail in a controlled environment. Driving behavior models, including both longitudinal and lateral movements of the vehicles, are key components of microscopic traffic simulation tools. The detailed level of vehicle movement in microscopic simulation models is needed to understand the underlying behavior at the formation of congestion and is necessary for evaluation the impact of various solutions on traffic flow.

Traffic flow characteristics in emerging and developing countries are substantially different from those in the developed countries, and so microscopic traffic models that are designed for homogenous traffic streams need to be adapted for these situations. This is exemplified by Fig. 1 . In homogenous traffic, vehicles are predominantly cars that follow the marked lanes. Traffic in emerging and developing countries is characterized by a wide mix of vehicles that includes motorized vehicles such as motorized two wheelers (MTW), auto-rickshaws (three-wheeled motorized vehicles), cars (including jeeps and small vans), buses, light commercial vehicles (LCVs), trucks, and nonmotorized vehicles such as bicycles and tricycles. These vehicles have wide varying dimensions and performance capabilities. This variety leads vehicles not to follow strict lane discipline and occupy any available space on the road. Smaller size vehicles, such as two-wheelers, often utilize gaps between vehicles $[8,9]$. As a result, the interactions among vehicles and the resulting manoeuvers they undertake are much more complex in mixed traffic conditions. Driving behavior models that describe these interactions are at the core of microscopic traffic simulation systems. Driving behavior models has been developed for more than half a century [10-12]. However, most of the available models are designed for homogenous traffic and so are not fully capable to reproduce traffic patterns that emerge in the presence of mixed traffic conditions. Reviews of these models in the context of homogeneous traffic can be found, for example, in Brackstone and McDonald [11], and Toledo [12].

This paper reviews the literature on driving behavior models that were specifically aimed for mixed traffic conditions. The models discussed include those for longitudinal and lateral movements and gap acceptance.

The rest of this paper is organized as follows: the next two sections reviews current models for longitudinal and lateral movements in mixed traffic. The following section discusses the limitations and gaps in state of the art models as well as data needs to support estimation of these models and improve their fidelity. The next section introduces new modeling framework and the final section summarizes our findings and conclusions.

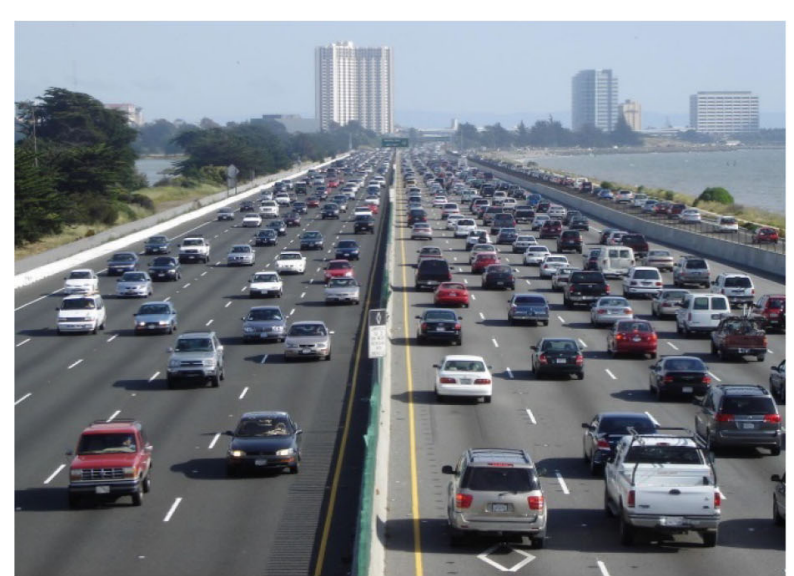

(a)

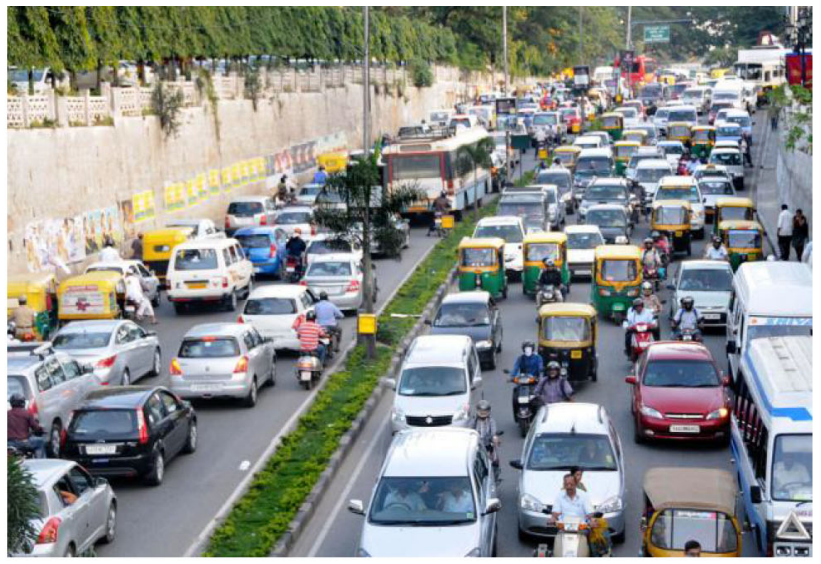

(b)

Fig. 1 Homogeneous and mixed traffic characteristics. a Homogeneous traffic. b Mixed traffic 


\section{Longitudinal Movement Models}

Longitudinal movement models commonly describe how a following vehicle reacts to the lead vehicle in the same lane. A large number of car following models have been proposed in the context of homogenous traffic. These may be classified based on behavioral assumptions, namely, stimulus response models [13-17] psycho-physical models $[18,19]$ and fuzzy logic based models [20]. Car following models have also been extended to more general acceleration models that also consider free flow situations in which the subject driver does not closely follow a leader.

Studies of longitudinal movement for mixed traffic suggest extensions of the car following paradigm is several ways: First, drivers may react differently to their leader depending on the combination of the types of the two vehicles (their own and the leader). Second, the lack of lane discipline in the traffic stream causes drivers to react not only to their leader but also to other vehicles on their sides. Furthermore, the lack of lane discipline and the variability in vehicle widths result in situations in which drivers do not strictly follow a leader. For example, drivers may follow their leader only partially in a staggered way. They may follow two leaders at the same time or be squeezing between two leaders. Finally, in road sections with unseparated bidirectional flow, drivers may also respond to oncoming traffic sharing the same roadway.

\section{Car Following Regimes}

Lan and Chang [21] developed a car following model for motorcycles using the General Motors (GM) [13, 14] model structure. They considered two cases: (1) only one leading vehicle in front; (2) two or more leading vehicles in front and neighboring-front (including either left-front, right-front, or both). In addition, an adaptive neuro-fuzzy inference system (ANFIS) was developed to capture the following behavior of motorcycle. They found that the ANFIS model performed better than the GM model.

Chakroborty et al. [22] proposed a longitudinal acceleration model that considers different driving behaviors in mixed traffic based on safety and urgency: free flow, car following, passing and presence of an opposing vehicle. The mathematical model is expressed by:

$$
\begin{aligned}
a_{n}\left(t+T_{n}\right)= & \alpha\left[\beta(t)\left\{k_{1} \frac{V_{s}(t)-V_{n}(t)}{T_{n}}-k_{2} \dot{U}(t)\right\}\right] \\
& +(1-\alpha)\left[\frac{V_{s}(t)-V_{n}(t)}{T_{n}}\right]
\end{aligned}
$$

where, $a_{n}\left(t+T_{n}\right)$ is the acceleration/deceleration at time $t+T_{n} . T_{n}$ is the perception/reaction time of the vehicle. $V_{s}(t)$ is the sustainable speed of the subject vehicle at time t. $V_{n}(t)$ is the subject's actual speed. $\dot{U}(t)$ is the rate of change of potential being faced by the subject. $\alpha$ is a state dummy variable that indicates whether or not the vehicle is constrained by dynamic obstacles (i.e., $\alpha$ is 0 for free flow and 1 for constrained flow). $k_{1}$ and $k_{2}$ are calibration constants. $\beta(t)$ is a sensitivity parameter.

The above equation depends on two terms: the deviation from the sustainable speed, which the driver feels comfortable driving at, and the rate of change of potential function. The potential function captures the magnitude of interaction with obstacles and other vehicles in the surroundings [23]. The interaction with obstacles depends on their characteristics. For example, the potential field due to a parked vehicle may be less pronounced than the potential field emanated by a truck coming in the opposing direction. The obstacles which are considered in the study are road edges, lane markings, static obstacles (e.g., potholes, parked vehicles) and dynamic obstacles (e.g., vehicles in the same and opposing directions). The results show that the model is capable to predict different driving regimes, from free flow to congested, in a single framework and to capture the effects of varying road geometry. However, the paper does not provide any details on the parameters' calibration.

Minh et al. [24] developed an acceleration model for motorcycles at signalized intersections. The model includes four driving regimes that are defined by combinations of car following or free flowing and acceleration or deceleration. Drivers are assigned to one of the four regimes based on the space headway to the leader. Free regime is invoked when distance headway is greater than the longitudinal threshold distance, otherwise the following-regime is applied. In free flow case, acceleration will be invoked when signal turns to green and deceleration regime is invoked when signal turns to red. In the following regime, the acceleration is invoked when relative speed is positive, otherwise deceleration regime is invoked. The acceleration in each regime is modeled using a generalization of the GM model $[13,14]$ framework. The model takes into account the effect of the gender of the motorcycle driver, the number of people riding the motorcycle and whether the leader is a motorcycle or a four-wheeler:

Free acceleration:

$a_{n}\left(t+T_{n}\right)=\alpha\left[V_{n}^{D S}-V_{n}(t)\right]+\varepsilon_{n}\left(t+T_{n}\right)$ 
Free deceleration: are the speeds of the follower

$a_{n}\left(t+T_{n}\right)=\lambda \frac{\left(V_{n}(t)\right)^{\eta}}{\left(\Delta X_{n}(t)\right)^{v}} v_{p}^{\delta_{n}^{p}} v_{g}^{\delta_{n}^{g}}+\varepsilon_{n}\left(t+T_{n}\right)$

Following acceleration:

$$
\begin{aligned}
a_{n}\left(t+T_{n}\right)= & \xi \frac{\left(V_{n}(t)\right)^{\varphi}}{\left(\Delta X_{n}(t)\right)^{\psi}}\left(\Delta V_{n}(t)\right)^{\lambda} \vartheta_{p}^{\delta_{n}^{p}} \vartheta_{g}^{\delta_{n}^{g}} \vartheta_{h}^{\delta_{n}^{h}} \\
& +\varepsilon_{n}\left(t+T_{n}\right)
\end{aligned}
$$

Following deceleration:

$a_{n}\left(t+T_{n}\right)=\xi \frac{\left(V_{n}(t)\right)^{\varphi}}{\left(\Delta X_{n}(t)\right)^{\psi}} \vartheta_{p}^{\delta_{n}^{p}} \vartheta_{g}^{\delta_{n}^{g}} \vartheta_{h}^{\delta_{n}^{h}}+\varepsilon_{n}\left(t+T_{n}\right)$

where, $a_{n}\left(t+T_{n}\right)$ is the acceleration/deceleration of the subject motorcycle at time $t+T_{n} . T_{n}$ is the subject's reaction time. $V_{n}(t)$ and $V_{n}^{D S}$ are the speed of the subject and its desired speed, respectively. $\Delta X_{n}(t)$ is the spacing between the subject and the leader or the stop line. $\lambda, \alpha, \xi$, $\phi$ and $\psi$ are parameters. $\delta_{n}^{p}, \delta_{n}^{g}$ and $\delta_{n}^{h}$ are the dummy variables associated with multiple riders on the motorcycle, the gender of the driver and four wheeler leaders, respectively. $v_{p}, v_{g}, \vartheta_{p}, \vartheta_{g}$ and $\vartheta_{h}$ are the parameters associated with these dummy variable. $\varepsilon_{n}\left(t+T_{n}\right)$ is a random error term.

The parameters of all components of the model were estimated jointly using the maximum likelihood method with trajectory data of individual vehicles. However, only 20 trajectory data points at a resolution of $0.2 \mathrm{~s}$ (thus covering only $4 \mathrm{~s}$ of travel) were available due to limited field of view. The results showed that accelerations and decelerations were larger in absolute values when the driver was alone on the motorcycle and when the lead vehicle is a four wheeler. Accelerations and decelerations were lesser for female drivers compared to male drivers.

Ravishankar and Mathew [25] included vehicle-type specific parameters for different combinations of leaders and followers in the Gipps's car-following model [15]. They studied all nine combinations of leaders and followers consisting of auto-rickshaws, cars and buses. They introduced type-specific parameters for the maximum comfortable acceleration and for the desired speed in the acceleration model and for the maximum deceleration in the deceleration model. In addition, different parameters for the sensitivity of the deceleration to the spacing between the vehicles were introduced for each leader-follower combination. The model parameters were estimated using trajectory data collected with GPS devices that were installed in pairs of vehicles that participated in following experiments. The estimation results showed that the smaller Auto-rickshaws-tend to maintain lesser space headways compared to larger vehicles.

\section{Other Following Regimes}

Several studies acknowledged that, in mixed traffic, drivers may not strictly follow their leader, but only be partially aligned with it, following multiple leaders or being between leaders. Cho and $\mathrm{Wu}$ [26] developed a model based on the concept of thrust and repulsion. In their model, the speed of the subject motorcycle is a function of its desired speed and current speed, the current speed of the leader, the space headway and a minimum safe headway:

$V_{n}(t+1)=V_{n}^{D S}\left(1-\exp \left(-\lambda \frac{\left(V_{n-1}(t)\right)^{\alpha}}{\left(V_{n}(t)\right)^{\beta}}\left(\frac{\Delta x_{n}(t)-S_{n-1}}{L}\right)^{\gamma}\right)\right)$

where, $V_{n}(t)$ and $V_{n-1}(t)$ are the speeds of the follower (subject) and the leader at time $t$, respectively. $V_{n}^{D S}$ is the desired speed of the follower. $\Delta x_{n}(t)$ is the space headway between the leader and the follower. $S_{n-1}$ is the minimum space headway at a standstill. $\alpha, \beta, \gamma, \lambda$ and $L$ are parameters.

In order to study the staggered following, a weight function that captures the lateral separation between the subject and leaders was introduced in the model. The model allows the possibility of two leader motorcycles (the nearest on the right-hand and left-hand sides). The speed of the subject vehicle is calculated using the following equation:

$V_{n}(t+1)=V_{n}^{D S}\left(\begin{array}{c}1-w\left(y_{r}(t)-y_{n}(t)\right) e^{-\lambda \frac{\left(V_{r}(t)\right)^{\alpha}\left(V_{n}(t)\right)^{\beta}}{\left(\frac{x_{r}(t)-x_{n}(t)-S_{r}}{L}\right)^{\gamma}}} \\ -w\left(y_{l}(t)-y_{n}(t)\right) e^{-\lambda \frac{\left(\frac{\left(V_{l}(t)\right)^{\alpha}}{\left(V_{n}(t)\right)^{\beta}}\left(\frac{x_{l}(t)-x_{n}(t)-S_{l}}{L}\right)^{\gamma}\right.}{L}}\end{array}\right)$

where, $w$ is the weight function. $y_{r}(t)$ and $y_{l}(t)$ are the lateral positions of the nearest lead vehicle on the right-hand and left-hand sides, respectively. $y_{n}(t)$ is the subject's lateral position.

This study considers multiple leaders and staggered following in the longitudinal behavior models. The limitation is that calibration and validation of the model from field data is not reported.

Lee et al. [27] developed a car following model for motorcycles that requires the driver to maintain a minimum gap that would allow it to stop in time to avoid a collision with the leader if it breaks to a stop. But, because motorcycles may be staggered with their leaders and can easily manoeuver laterally, the model also allows them to keep shorter following distances if these allow them to dodge the crash by moving laterally, as shown in Fig. 2. The minimum distances are calculated in both cases based on equations of motion under constant decelerations:where, $S_{n}^{\min }(t)$ is the minimum following gap. $V_{n-1}(t)$ and $V_{n}(t)$ are speeds of the leader 


$$
S_{n}^{\min }(t)=\min \left\{\begin{array}{c}
T_{n}-\frac{V_{n}^{2}(t)}{2 b_{n}}+\frac{V_{n-1}^{2}(t)}{2 b_{n-1}} \\
\Delta V_{n}(t)\left(T+\frac{d_{n}(t)}{v_{n}}\right)+\frac{1}{2}\left(b_{n}^{\prime}-b_{n-1}\right)\left(\frac{d_{n}(t)}{v_{n}}\right)^{2}-\frac{1}{2} b_{n-1} T\left(T+\frac{2 d_{n}(t)}{v_{n}}\right)
\end{array}\right\}
$$

and follower, respectively. $\Delta V_{n}(t)$ is the speed difference between the two (speed of the subject less than the speed of the leader). $b_{n-1}$ and $b_{n}$ are their decelerations when braking to a stop. $b_{n}^{\prime}$ is the deceleration of the subject motorcycle when moving laterally. $T_{n}$ is the reaction time. $d_{n}(t)$ is the lateral movement needed by the subject in order not to overlap laterally with the leader. $v_{n}$ is the lateral speed.

The authors also introduced a model for the minimum following gap in oblique following for cases that the subject does not laterally overlap with the leader, as shown in Fig. 3. The model assumes that there are minimum longitudinal and lateral gaps that the subject would maintain if strictly behind or parallel to the leader. When the subject is oblique to the leader, the minimum space gap would be defined by a linear interpolation of these two values. The minimum longitudinal and lateral gaps are given by:

$S_{n}^{\text {long }}(t)=S_{o}^{\text {long }}+\alpha_{1}^{\text {long }} \Delta V_{n}(t)+\alpha_{2}^{\text {long }} V_{n-1}(t)$

$S_{n}^{\text {lat }}(t)=S_{0}^{\text {lat }}+\alpha_{1}^{\text {lat }} \Delta V_{n}(t)$

It is assumed that vehicles follow elliptical path in oblique following behavior. The equation of elliptical curve is described as follows:

$S_{n}^{\text {oblique }}(t)=\frac{S_{n}^{\text {long }}(t) S_{n}^{\text {lat }}(t)}{S_{n}^{\text {long }}(t) \sin \theta \cdot S_{n}^{\text {lat }}(t) \cos \theta}$

where, $S_{n}^{\text {long }}(t) S_{n}^{\text {lat }}(t)$ and $S_{n}^{\text {oblique }}(t)$ are the minimum longitudinal, lateral and oblique gaps, respectively. $\theta$ is the following angle. $S_{o}^{\text {long }}, \alpha_{1}^{\text {long }}, \alpha_{2}^{\text {long }}, S_{0}^{\text {lat }}$ and $\alpha_{1}^{\text {lat }}$ are parameters. The more constraining minimum longitudinal distance among $S_{n}^{\min }(t)$ and $S_{n}^{\text {oblique }}(t)$ is used as the safety margin in the calculation of accelerations using Gipps'

S
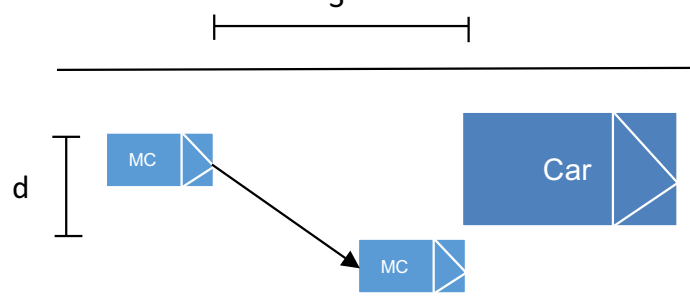

Fig. 2 Lateral movement for collision avoidance (adopted from [27]) model [15]. The longitudinal headway model and the oblique and lateral headway models were calibrated by using detailed vehicle trajectory data.

Jin et al. [28] proposed a modification to the optimal velocity model [19] to capture staggered car-following situations (Fig. 4). The modified model takes into consideration the extent of lateral overlap between the leader and follower with additional time to collision. The mathematically model for acceleration is given as follows:

$a_{n}\left(t+T_{n}\right)=\alpha\left[V^{o p t}\left(\theta_{n}(t)\right)-V_{n}(t)\right]-\frac{\lambda}{T T C_{n}(t)}$

where, $a_{n}\left(t+T_{n}\right)$ is the acceleration of the subject vehicle, $T T C_{n}(t)$ is the time to collision. $\alpha$ and $\lambda$ are parameters. $V^{\text {opt }}\left(\theta_{n}(t)\right)$ is the subject's optimal velocity, which depends on the width of the leader and visual angle and can be written as:

$V^{\text {opt }}\left(\theta_{n}(t)\right)=V_{1}+V_{2} \tanh \left\{C_{1}\left[w_{n-1} / \theta_{n}(t)\right]-C_{2}\right\}$

where, $V_{1}=6.75 \mathrm{~m} / \mathrm{s}, \quad V_{2}=7.91 \mathrm{~m} / \mathrm{s}, \quad C_{1}=0.13 \mathrm{~m}^{-1}$, and $C_{2}=1.57$ are parameters that were obtained in a previous study [29].

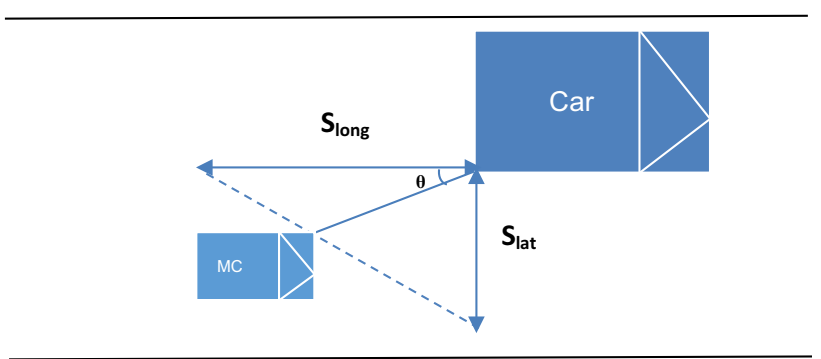

Fig. 3 Oblique following (adopted from [27])

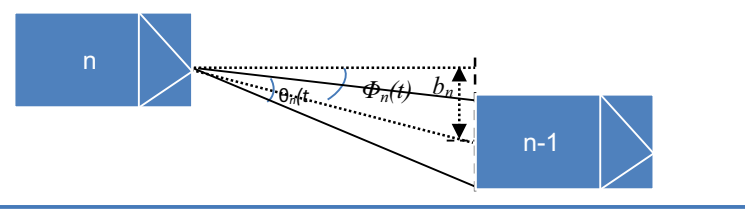

Fig. 4 Staggered car following (adopted from [28]) 
Another vehicle or roadway edge

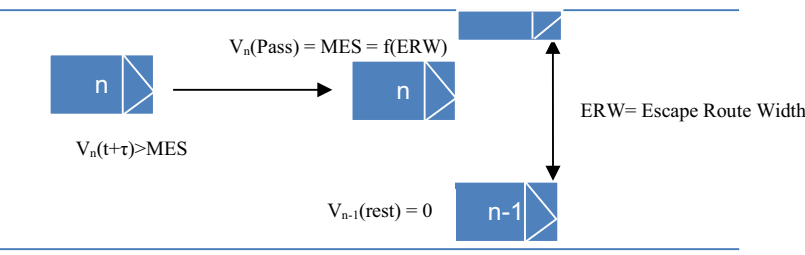

Fig. 5 Speed to allow squeeze pass the leader (adapted from [30])

The TTC variable takes into account lateral separation effects. It can be expressed as:

$\frac{1}{T T C_{n}(t)}=\frac{\theta_{n}^{\prime}(t)}{\theta_{n}(t)}-\frac{\varphi_{n}^{\prime}(t)}{\varphi_{n}(t)}$

$\theta_{n}(t)=\frac{w_{n-1}}{\Delta x_{n}(t)-l_{n-1}}$

$\varphi_{n}(t)=\arctan \frac{b_{n}}{\Delta x_{n}(t)-l_{n-1}}$

where, $\theta_{n}(t)$ is the visual angle which is observed by the driver of the $n$th vehicle at time t. $\varphi_{n}(t)$ is the visual gap angle separating the leader from the moving direction of the subject. $\Delta x_{n}(t)$ is the distance headway between the leader and subject. $b_{n}$ is the lateral separation distance between the two vehicles. $l_{n-1}$ and $w_{n-1}$ are the length and width of the leader, respectively.

The authors conducted stability analysis of the proposed model. However, they did not estimate or validate their model with real-world data.

Gunay [30] proposed a car following model that considers the lateral friction with surrounding vehicles. In this model, the subject vehicle chooses a maximum speed that, in order to avoid crashing with a leader that brakes to a stop, would allow it to either squeeze between two leaders or to shift laterally from the path of the leader. Squeezing between two leaders can occur at a Maximum Escape Speed (MES), which depends on the lateral clearance between the leaders (Fig. 5):

$$
\begin{aligned}
M E S & =-17.2(F C)^{2}+77.6(F C)-0.7 \\
0.5 & <F C<1.5
\end{aligned}
$$

The maximum speed that would allow the driver to undertake the squeezing manoeuver is given by Gipps' model framework [15]:

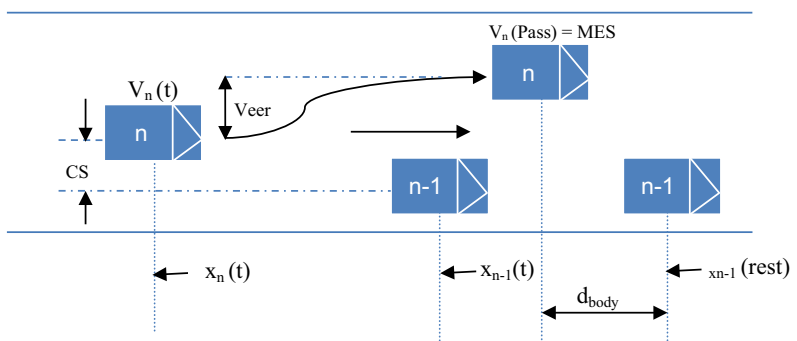

Fig. 6 Speed to allow partial lane change (adapted from [30])

where, $V_{n}(t)$ and $V_{n-1}(t)$ are the speeds of the subject and the leader, respectively. $T_{n}$ is the subject's reaction time. $b_{n}$ and $b_{n-1}$ are the deceleration rates of the subject and the leader, respectively. $x_{n}(t)$ and $x_{n-1}(t)$ are the positions of the subject and leader, respectively. $S_{n-1}$ is the length of the leader vehicle.

At the same time, the driver should also be able to veer laterally to avoid crashing with the leader, as shown in Fig. 6 . The maximum speed that would allow the subject to veer and avoid a crash with the leader if it comes to a stop is given by:

$V_{n}\left(t+T_{n}\right) \leq 2 \frac{x_{n-1}(\text { rest })-x_{n}(t)-\frac{V_{n}(t)}{2} T_{n}-\frac{t_{\text {veer }}}{2} M E S-d_{\text {body }}}{t_{\text {veer }}+T_{n}}$

where, $x_{n-1}($ rest $)$ is the position of the leader after coming to a stop. $t_{\text {veer }}$ is the time taken for the veering manoeuver, which depends on the veering distance. $d_{\text {body }}$ is the distance between the center of bodies of the two vehicles, at the time that the passing takes place.

The study presents this theoretical framework, but does not make any attempt to estimate the model parameters with field data.

In summary, several authors have proposed modifications and variants of strict car following models that have also been used in modeling homogeneous traffic that capture the differences between various vehicle types that are present in the mixed traffic stream. Others, have suggested models for non-strict following situations, such as staggered following [26-28, 30] and passing behavior [30]. Only limited research has been done to integrate these various regimes in a unified following model framework. In terms of data and estimation, some of the proposed models e.g.,

$V_{n}\left(t+T_{n}\right) \leq b_{n} T_{n}+\sqrt{\left(b_{n} T_{n}\right)^{2}-2 b_{n}\left\{V_{n}(t) \frac{T_{n}}{2}+\frac{M E S^{2}}{2 b_{n}}+\frac{V_{n-1}^{2}(t)}{2 b_{n-1}}+x_{n}(t)-x_{n-1}(t)+S_{n-1}\right\}}$ 
[22, 27, 28, 30] require difficult to collect data, such as on visual angles, escape and veering speeds. Minh et al. [24], Lee et al. [27] and Ravishankar and Mathew [25] used trajectory data for estimation and validation of their models. The lack of such data dictated that other studies relied on macroscopic data for the model calibration and validation.

\section{Lateral Movement Models}

Lane changing models describe the dynamics of lateral movement behavior of vehicles. They incorporate the decision to initiate a lane change and its execution. The distinction between the wish to change lanes and the execution of the lane change was introduced by Sparmann [31]. Lane changing may be mandatory (MLC) or Discretionary (DLC). MLC lane change are those that the driver must take, for example in order to turn at an intersection or avoid obstacles. DLC are motivated by the drivers' desire to improve their current driving conditions by overtaking a slow vehicle or having a shorter queue. This structure was implemented in CORSIM [36].

Lane changing models are often based on decision rules (Gipps [32], SITRAS [33, 34], Wei et al. [35]). In this approach, drivers select lanes by comparing the acceptable lanes with respect to, a hierarchy of considerations, such as downstream lane blockages, lane use restrictions, the locations of obstructions, the presence of heavy vehicles, and potential speed gains. Other studies (e.g., Yang [37], Ahmed [38] and Toledo [39]) used the random utility theory, which captures trade-offs among the various considerations, to describe the lane selection behavior. These models are commonly estimated using the maximum likelihood approach based on vehicular trajectory data.

\section{Lateral Shift Behavior Under Mixed Traffic Conditions}

Conventional lane-changing models are designed for lanebased movements. They cannot describe the lateral movements of mixed traffic adequately. Due to non-lane discipline and smaller size of vehicles, lateral movements occur also without changing lanes entirely. The following studies describe lateral movement behavior for mixed traffic.

Malikarjuna et al. [40] studied the lateral gap maintaining behavior in heterogeneous traffic conditions. In this study, the data was extracted using video image processing software, TRAZER. The data was collected for different road widths ranging from 6.60 to $12.50 \mathrm{~m}$. Four vehicle combinations were considered such as light motorized vehicle (LMV)-Two-wheeler (TW), TW-LMV, LMV-
LMV, TW-TW. Lateral gaps from left side and right side of the subject vehicle were considered. The following factors were considered in this study: speeds and types of subject vehicle and adjacent vehicles. The results of the study are that if the speed of the adjacent vehicle increases, lateral gap between subject vehicle and adjacent vehicle increase. This study focuses only on empirical results and does not deal with any driver behavior model.

Luo et al. [41] studied the interaction between cars and bicycles in heterogeneous traffic conditions. They developed a cellular automata (CA) model with an occupancy rule based on lateral gap of mixed traffic. Bicycles move laterally within the bicycle lane or to the cars lane, with different required gaps. Using traffic video data that were collected in Beijing, China, they developed a regression model to find needed lateral gaps based on speed of the car. The study results show that lateral gaps increase with an increase in speed. The study set up was limited to a situation that cars and bicycles move in fixed lane for each type.

Cho and $\mathrm{Wu}$ [26] proposed a lateral movement model for motorcycles that assumes drivers try to modify their positions to get the maximum lateral space and the motivation decides the lateral movement. Lateral position of a motorcycle (Vehicle N) was decided by the positions of the nearest vehicles at front left (vehicle $\mathrm{J}$ ), front right (vehicle I), adjacent left (Vehicle L), adjacent right (Vehicle R), rear left (Vehicle Q), and rear right (Vehicle P) as shown in Fig. 7. The following factors which affect the lateral movement model are longitudinal and lateral position of surrounding vehicles, vehicle performance and maximum steering angle. The vehicle will modify its lateral position to the middle of those vehicles surrounding it.

The lateral movement model developed by Chakroborty et al. [22] uses the maximum steering angle and speed of the vehicle to define a set of accessible points for the subject vehicle. Among these points, the driver chooses the

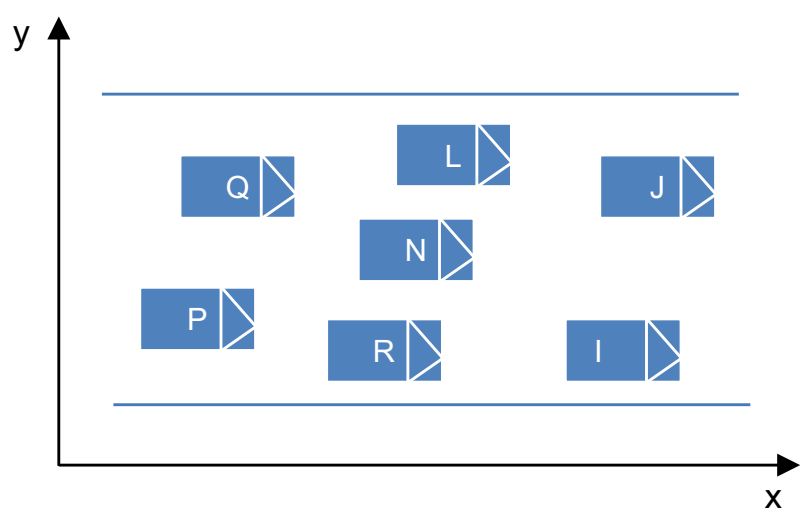

Fig. 7 Vehicles on a motorcycle lane-lateral movement (adopted from [26]) 
one that has the least interaction with other vehicles and obstacles. Calibration of the model parameters was not discussed.

Oketch [42] presents a model for mixed-traffic streams with motorized and non-motorized vehicles. The lateral movement decisions are governed by fuzzy logic rules. The decision process of lateral movement is modeled using three steps: (1) identification of options (2) their evaluation by fuzzy logic and (3) testing the safety criteria (available gaps) before execution of the actual manoeuver. The lateral movement evaluation considers avoiding obstructions, directional movement requirements, avoiding slow moving vehicles and gaining speed and queue advantage. The model incorporates gradual lane change manoeuver (as opposed to an instantaneous one), by assuming lateral speed of $1.0 \mathrm{~m} / \mathrm{sec}$ for each vehicle. Validation and calibration of the model were carried out with macroscopic data (delay, queue lengths, mid-link speeds and link travel times) from Nairobi, Kenya.

Mathew et al. [43] proposed a modeling framework using the concepts of strips to capture the lateral movements. The benefit from changing strips stems from the difference between the safe speeds on the two strips as computed using the car-following model. In order to represent tactical lateral movement, the driver evaluates multiple strip changes. The benefit of each strip depends on the speed advantage and decays with the number of required strip changes:

$b_{s_{n}(t)}=\frac{v_{\text {safe }}\left(t, s_{n}\right)-v_{\text {safe }}\left(t, s_{c}\right)}{v_{\max , \mathrm{s}_{\mathrm{c}}}} \times e^{-\lambda \times s}$

where, $b_{s_{n}(t)}$ is the benefit of changing to strip $s_{n} . s_{c}$ is the current vehicle's strips. $v_{\text {safe }}$ and $v_{\max }$ are the safe speed and the maximum speed in the strip. $s$ is the number of strip changes to $\operatorname{strip} s_{n} . \lambda$ is a parameter.

The model was validated using macroscopic data (throughput, average speed and travel time) that were collected in Mumbai, India.

Some of the studies model the lateral movement behavior of vehicles using discrete choice models. For example, Lee et al. [27] developed a model for lateral movements of motorcycles using path choice model. Such path choice behavior is described by using a Multinomial Logit model. There are three alternatives in the choice set: shifting leftward, keeping straight, and shifting rightward. These alternatives are formulated based on the speed of the vehicle in front, interacting force with the front and rear vehicles, size of the vehicle near the path, lateral distance to the ready to overtaken position, lateral clearance beside the preceding vehicle. The lateral movement distance for the next time step was calculated based on lateral speed of the vehicle. The models were calibrated on the basis of trajectories of motorcycles recorded at a section of the
Victoria Embankment in central London. But in this study, only lateral movement behavior of motorcycles was studied.

Siddique [44] developed discretionary and mandatory lateral movement models under week lane-discipline conditions using a multinomial logit (MNL) model. The road was divided into a number of strips with a width of $0.5 \mathrm{~m}$, which formed the discrete alternatives. The variables considered in the model included the subject vehicle type, speed, lead vehicle type and follower vehicle type, position of the road, type of movement and mandatory critical zones. It was estimated with trajectory data that were collected from two locations of Dhaka, Bangladesh. The results show that non-motorized slow-moving vehicles prefer to stay on the left (slow) side of the roadway whereas other vehicles tend to move on the right (fast) side with an expectation to gain speed. A limitation of the data used in the study is that due to limited field of view of the cameras used to collect the data, it was not possible to record the movement of the vehicle for a long distance.

Munigety et al. [45] presents a lateral movement model for different vehicle types such as motorcycles, cars, autorickshaws and heavy vehicles using discrete choice analysis. The framework of the lateral-shift decision model is described using a Multinomial Logit model. There are three alternatives in the choice set: shifting leftward, keeping straight, and shifting rightward. The explanatory variables of the model are speed of the vehicle ahead, gap and size of the vehicle in front. These models are estimated using detailed vehicle trajectory data that was collected in mixed traffic driving conditions. The output of the study in the context of speed gain is that cars and two-wheelers preferred faster path whereas; heavy vehicles and threewheelers preferred slower path. This implies that heavy vehicles and three-wheelers may change their current path in order to prevent obstructing the fast moving vehicles which approaching from the rear. The longitudinal gap turned out to be an insignificant variable for two-wheelers in the context of space gap. This may be due to its smaller size which allows it to enter any convenient path once it finds a sufficient lateral gap.

In summary, Oketch [42] has dealt with mandatory lateral shift and other studies have dealt with discretionary lateral shift. Several authors proposed discrete lane change models that are similar to those used with homogeneous traffic conditions. Oketch [42], Mathew et al. [43] and Siddique [44] applied these concepts on a finer scale by dividing the roadway into a number of narrower strips (corresponding to the width of a motorcycle). The vehicle moves laterally discretely between these strips. Continuous lateral movement models may provide a more realistic description of this behavior. Lee et al. [27], Siddique [44] and Munigety et al. [45] used trajectory data to estimating 
the direction of lateral shift through discrete choice models. The lack of such data dictated that other studies were not estimated with real-world data.

\section{Gap Acceptance Models}

Gap acceptance models describe whether there is a sufficient gap present for the vehicle to execute the desired lane change or shift manoeuver. In these models, the driver compares the available gap between the vehicles in the desired lane with a corresponding critical gap, the driver will invoke lane change if the available gap is larger than the critical gap. Critical gaps are modeled as random variables using various distributions in order to capture its variability across drivers. Drew et al. [46], Cohen et al. [47] and Solberg et al. [48] used the lognormal distribution to describe critical gap. Miller [49] assumed it to be normally distributed. The influence of different traffic factors on critical gaps was discussed in several studies [50-53]. Ahmed [38] allowed different sets of parameters for MLC and DLC situations. Choudhury et al. [54] and Hidas [55] distinguished between normal and forced lane changing, in which the subject vehicle forces the lag vehicle to decelerate.

Most studies related to gap acceptance model in the context of mixed traffic deal with yield controlled intersection crossing behavior. They mostly use constant critical gaps that differ between various categories of vehicles (e.g., Popat et al. [56], Raghavachari et al. [57]). Similarly, Agarwal et al. [58] used different constant critical gap values for trucks/buses, cars/two-wheelers, auto-rickshaw, and cycles. Kumar and Rao [59] distinguished between critical gaps on the near and far lanes at the intersection.

Sangole et al. [60] used Neuro-Fuzzy technique to model the gap acceptance behavior of right turning twowheelers at three-legged intersections. Data for this study were collected at two three-legged right angled intersections in Aurangabad, India. The gap acceptance decisions depend on the size of lag/gap, age of the driver, conflicting vehicle type, and the vehicle occupancy. The study found that two-wheelers accept gaps as short as $1 \mathrm{~s}$. Large gaps over $9.5 \mathrm{~s}$ were accepted in all cases.

Several studies incorporate the variations in the critical gap by assuming that they follow some probability density function. For example Hossain [61], within the MIXNETSIM model for roundabouts, used a lognormal distribution model following analysis of field data from Dhaka, Bangladesh. In the simulation model, each driver is assigned different critical lags/gaps from this distribution. The model was validated using data on the travel times of vehicles through the roundabouts and macroscopic relationships of the flows circulating flows.
Pawar and Patil [62] analyzed gaps and lags at fourlegged partially controlled intersections in India. They estimated critical gaps using several different estimation methods. Critical lags and gaps vary and depend on the subject vehicle type, speed, position of the conflicting vehicle. Depending on the method of estimation temporal were estimated between 2.8 and $3.9 \mathrm{~s}$, ans spatial critical gaps were between 31.8 and $36 \mathrm{~m}$. These values are smaller than similar values reported in developed countries indicating drivers' aggressiveness in India.

Ashalatha and Chandra [63] proposed an alternative definition of critical gaps using the clearing behavior of vehicles. They defined a rectangular conflict zone which has the width of the lane and a length which is related to the length of the crossing vehicle (Fig. 8). It is assumed that the critical gap is the time needed for the crossing vehicle to clear this area. Estimation results using this definition yielded critical gaps that were lower than those given in HCM but greater than those estimated by standard critical gap estimation methods.

Kanagaraj et al. [64] studied merging manoeuvers at Tjunctions under congested traffic conditions. They developed probabilistic merging models. This is one of the first attempts to investigate merging behavior under mixed traffic conditions. The critical gap functional form was expressed as follows:

$G_{c r n}^{M}(t)=\exp \left[\beta^{M} X_{n}(t)\right]+\varepsilon_{n}^{M}(t)$

where, $G_{c r \mathrm{n}}^{M}(t)$ is the critical gap for merging. $X_{n}(t)$ and $\beta^{M}$ are the vector of explanatory variables that affect critical gaps and the corresponding parameters, respectively. $\varepsilon_{n}^{M}(t)$ is anormally distributed random term.

The explanatory variables used in the model included the lead, lag and subject vehicle type, the speeds of the lead and lag vehicles, the subject's waiting time and the traffic volume on the main road. The model was calibrated and validated using field data collected in Chennai, India. The

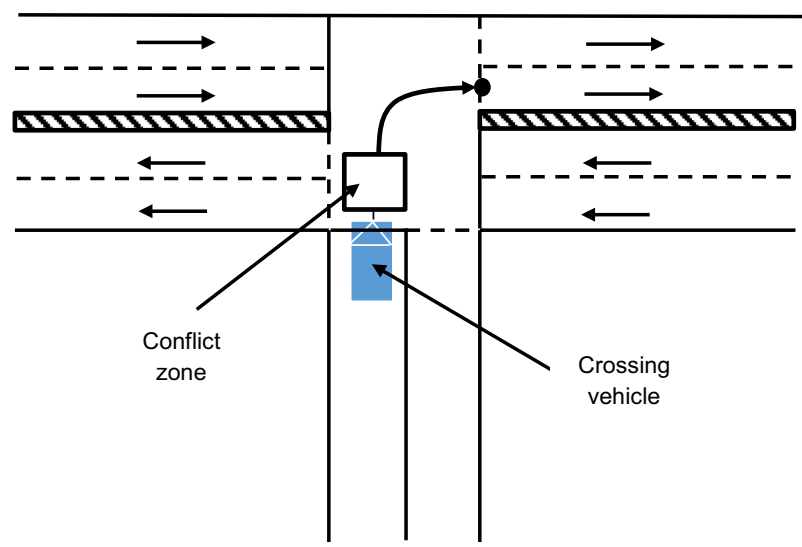

Fig. 8 Schematic representation of conflict zone (adapted from [63]) 
results showed that the critical gaps for smaller vehicles are smaller than those for cars.

Kanagaraj et al. [65] studied two unique merging processes which are commonly observed in mixed traffic: group and vehicle cover merging. Probabilistic models for these behaviors were developed. In group merging several vehicles merge in the same gap at the same time. Critical gaps for this case depended on the lead and lag vehicle speeds, the gap between the lead and lag vehicle, the number of vehicles in the group and the time it has been waiting to merge. Vehicle cover merging describes a situation that a vehicle merges under the cover of another (often larger) vehicle that interferes with the lag vehicle. Critical gaps in this situation depend on the lateral gap longitudinal and lateral gaps, the lead vehicle type and the subjects' waiting time.

The models were estimated and validated using field data collected in Chennai city, India. Two-wheelers were found to be more likely to accept use these merging behaviors compared to auto-rickshaw. Vehicles tended to accept smaller gaps when the lead vehicle is a twowheelers compared to cars and auto-rickshaws. Similarly, two-wheeler tended to reject gaps more when the lag vehicle is a car.

In summary, gap acceptance studies in the context of mixed traffic focus on intersection crossing and merging behavior. They do not describe the lateral shift process in mid-block sections. The developed models generally adopt the gap acceptance framework used in the context of homogeneous traffic conditions, but with additional explanatory variables, mostly in order to capture differences in behavior among different vehicle types. As with homogeneous traffic models, in congested conditions, cooperative and forced lateral shifts may also take place. These have been modelled by Kanagaraj et al. [64]. Hence, in this context as well, there is a need for a unified model that describes lateral movement including both lateral shift and gap acceptance behavior.

\section{Challenges and Research Directions}

There are two important characteristics that distinguish mixed traffic flow from homogenous traffic: the presence of a mix of widely variable vehicle types, and organization of lane-less traffic. The mix of vehicles can be captured by developing type-specific driving behavior models. For example, Lee et al. [27] developed behavior models specifically for motorcycles. Alternatively, type-specific parameters may be added to generic driving models. For example, Asaithambi et al. [66] and Mathew and Ravishankar [67] simulated mixed traffic using vehicle typespecific parameters in car following models. The non-lane

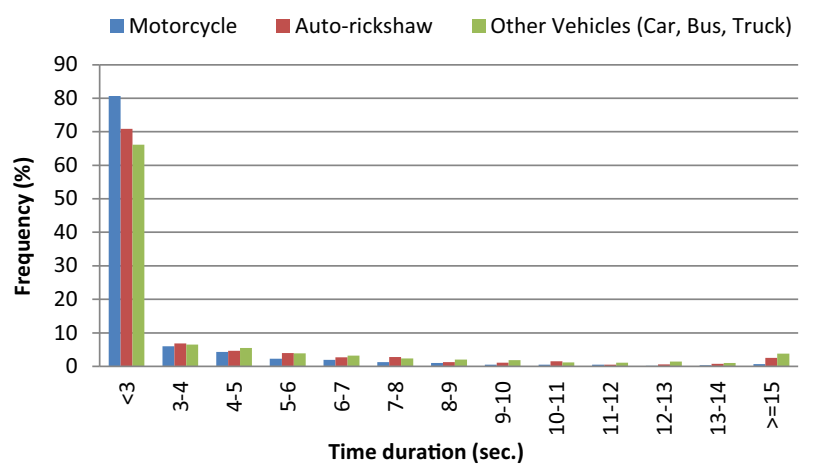

Fig. 9 Frequency of same leader present for different types of following vehicle

based movements of vehicles have also been studied in the literature. The lateral movement of vehicles results, especially for two-wheelers that the leader-follower pair changes frequently. Figure 9 shows the distribution of duration that various vehicle types are behind the same leader [68]. The figure shows that following episodes tend to be very short. $80 \%$ of two-wheeler will follow the same leader for less than $3 \mathrm{~s}$, whereas only 70 and $66 \%$ of autorickshaw and larger size vehicle. This may be due to motorcycle's smaller size and better manoeuverability. At the other end of the distribution, $15 \%$ of larger size vehicles and $11 \%$ of auto-rickshaws follow the same leader for more than $8 \mathrm{~s}$. But, only $5 \%$ motorcycles experience similar following episodes. The results imply significant lateral movements in the traffic stream and suggest that the two-dimensional movement of vehicles need to be integrated in a comprehensive driver behavior model. To this end, several research directions to advance driver behavior models for mixed traffic flows, through improved modeling, data collection and model estimation, are discussed next.

\section{Driver Behavior Models}

Some directions for improvement of the specification of state-of-the-art models are as follows:

1. Driving regimes A wider range of driving regimes exists in mixed traffic streams. For example, in the longitudinal movement, drivers may not only strictly car follow, but also have different interaction regimes with their leaders. These regimes need to be first clearly defined, for example, using the extent of lateral overlap or gap with the leader as a classifying variable. Figure 10 shows examples of various following regimes:

- Car following In this case, the lag vehicle (car) strictly following with leader (car). 


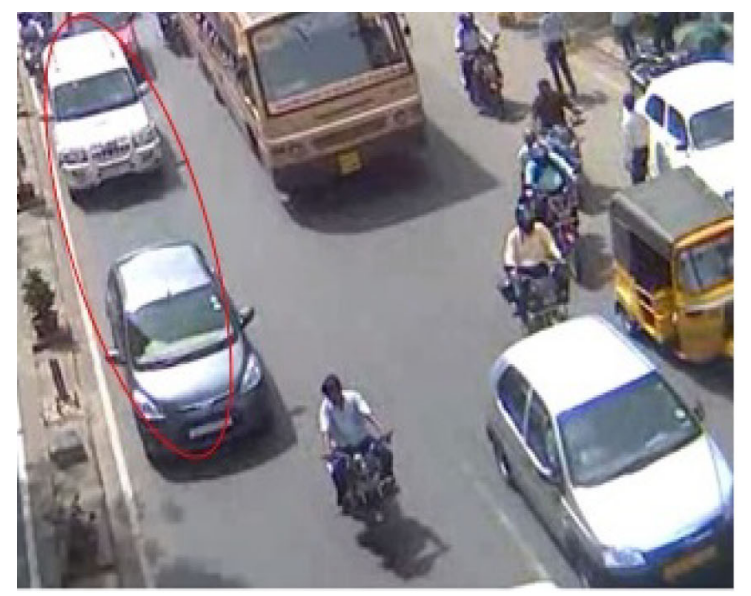

(a)

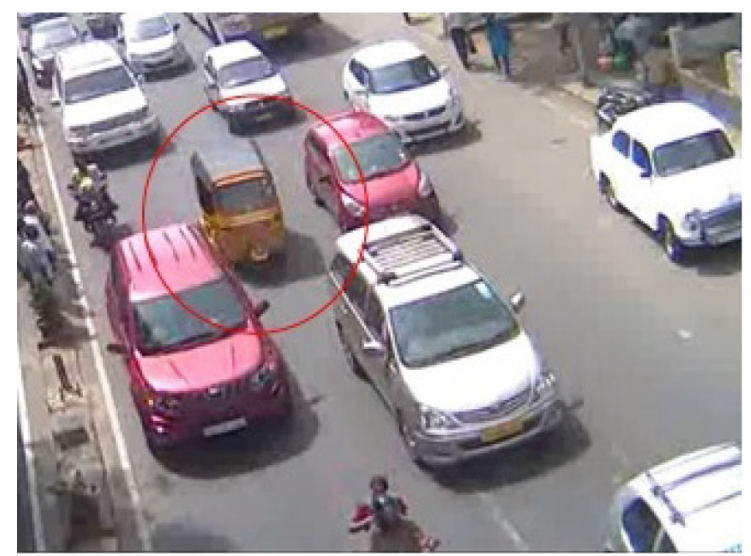

(c)

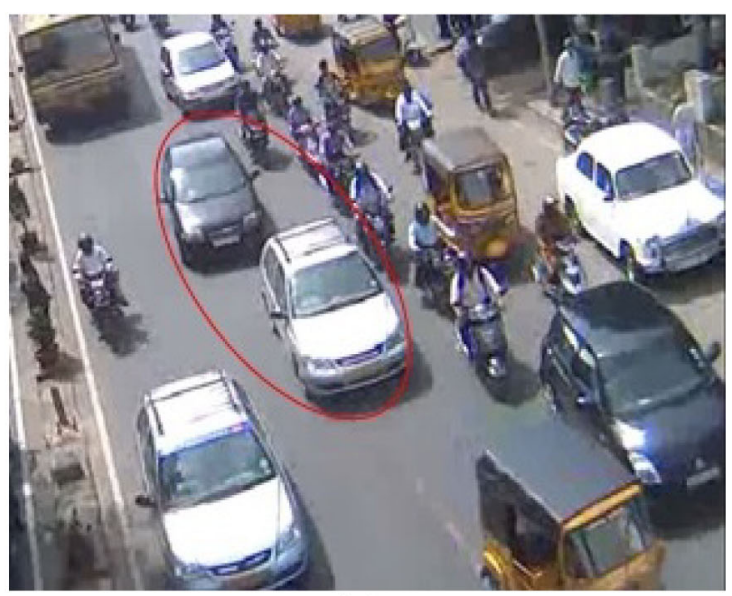

(b)

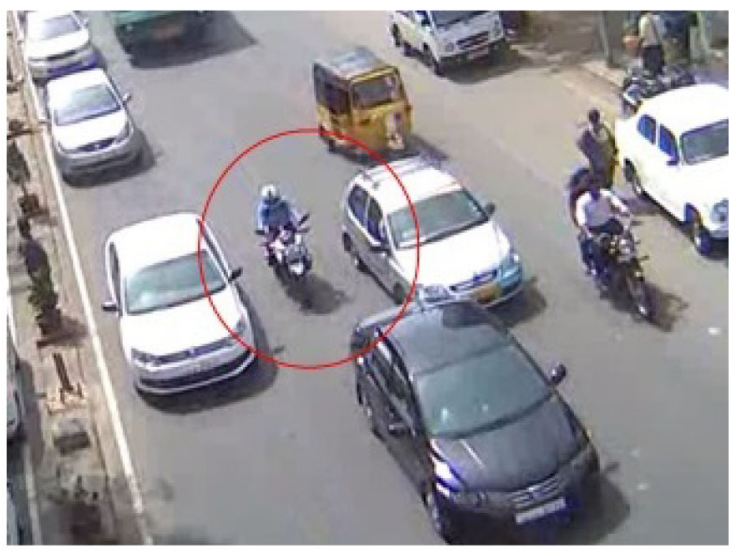

(d)

Fig. 10 Following behaviors in mixed traffic. a Car following, b staggered following, $\mathbf{c}$ following between two vehicles, $\mathbf{d}$ passing

- Staggered following Due to lane-less traffic and different type of vehicles, the following vehicle (car) is staggered with the leader vehicle (car), which implies looser following, and a better field of view and opportunities to initiate lateral shifts.

- Following between two vehicles In mixed traffic, vehicles occupy any lateral position on roadway, based on space availability. Hence, the subject vehicle (auto-rickshaw) follows between two leaders (car and car). This also allows better field of view and opportunities to pass between two vehicles or initiate lateral shifts.

- Passing Passing is a typical behavior of twowheelers in mixed traffic due to their narrow size and high manoeuverability. The existence of this behavior pattern has been pointed out in several studies [42, 69-72].

2. Multiple leaders Due to non-lane based movement and different vehicle sizes, a vehicle may follow multiple leaders. Following models need to identify the lead vehicle that affects the subject vehicle movement to a greater extent. To the best of our knowledge, the effect of multiple leaders has not been incorporated in the existing models.

3. Adjacent vehicles In homogenous traffic following models, the subject vehicle considers only the leader in the same lane. It is commonly assumed that adjacent vehicles in other lanes do not affect the longitudinal movement. This assumption is less reasonable in in mixed traffic. Vehicle's movement may be affected by adjacent vehicles. For example in the passing situation (Fig. 10d), the speeds of the passing vehicle may be affected by the lateral gap between the adjacent vehicles. The effect of adjacent vehicles was proposed by Gunay [30], but is absent in most other studies.

4. Lateral movement Lateral movement is often modeled in discrete lanes or strips. Several authors (Oketch et al. [42], Arasan and Koshy [9], Kanagaraj et al. [73], Asaithambi et al. [74]) assumed a constant lateral speed (e.g. $1 \mathrm{~m} / \mathrm{sec}$ ). Siddique [44] assumed move 
discretely between strips (each $0.5 \mathrm{~m}$ wide). Mathew et al. [43] also assumed discrete lateral movement allowing vehicles to move only one strip at a time. The different vehicles types in the traffic stream vary widely in their dynamic capability, which affects their lateral movement. For example, motorcycle can move laterally much faster compared to larger size vehicles. Hence, lateral movement models may be extended to account for these differences in speed and manoeuverability.

5. Lateral shift processes Due to the non-lane based conditions, lateral shifts occur frequently in mixed traffic streams, and therefore need to be modeled in detail. As with homogenous flow, these can take place using in different processes, such as normal, forced and cooperative lateral shifts. These also differ in the effect on other vehicles and traffic flow. Kanagaraj et al. [64] studied normal and forced merging behavior at intersections. However, more research is needed on these shift mechanisms and in more general settings.

6. Desired lateral positioning Several authors (e.g., [44, 68]) showed that drivers have preferred lateral positions in different situations. For example, cars tend to prefer the far side of the roadway that offers higher speeds and lesser friction with other vehicle types and obstructions (e.g., parked vehicles, bicycles and pedestrians). Motorcycles and auto-rickshaws tend to keep to the near side. Driver behavior models should be developed that capture the lateral position preferences.

\section{Model Estimation and Trajectory Data}

Driving models in homogenous traffic have been estimated with econometric methods and using detailed trajectory data (e.g., Toledo et al. [75], Choudhry [76]) However, in the context of mixed traffic calibration and validation have mostly been based on macroscopic flow characteristics, such as flows, speeds and densities [8, 9, 66, 77]. This approach limits the level of detail that can be captured in the developed models. Few studies utilized trajectory data, but these are often small samples collected for a specific study and for limited field of view [27, 64, 78].

Trajectory data are obtained using the video recordings [38, 79, 80] and naturalistic studies [81]. FHWA'S Next Generation Simulation project [82] shared several datasets of vehicle trajectories collected on expressway and urban arterials in US. These have been used extensively to calibrate and validate driving behavior models [83-87], among others for homogeneous traffic. To the best of our knowledge, limited vehicle trajectory data are available in the context of mixed traffic. This may, to a large extent, be due to the difficulty and high cost involved in data collection and extraction, and the technical complexities associated with having a wide mix of vehicles types with varying physical dimensions and dynamics characteristics (speed and acceleration capabilities) and non-lane based movement. Few studies involved collection of mixed traffic trajectory data. Lee et al. [27] extracted trajectories of 2019 motorcycle and other vehicles on an 80 meters section in London. Mallikarjuna et al. [88] used TRAZER an automated image processing system to extract trajectories from video records. They collected $6 \mathrm{~h}$ of data from a $25 \mathrm{~m}$ section of a road in Delhi, India. Munigety et al. [45] collected trajectories of 3173 vehicles on a $320 \mathrm{~m}$ road section in Mumbai, India. A recently collected data set that was collected by Kanagaraj et al. [68] is available as open source at http://toledo.net.technion.ac.il/mixed-traffic-tra jectory-data/. This dataset includes 3005 vehicle

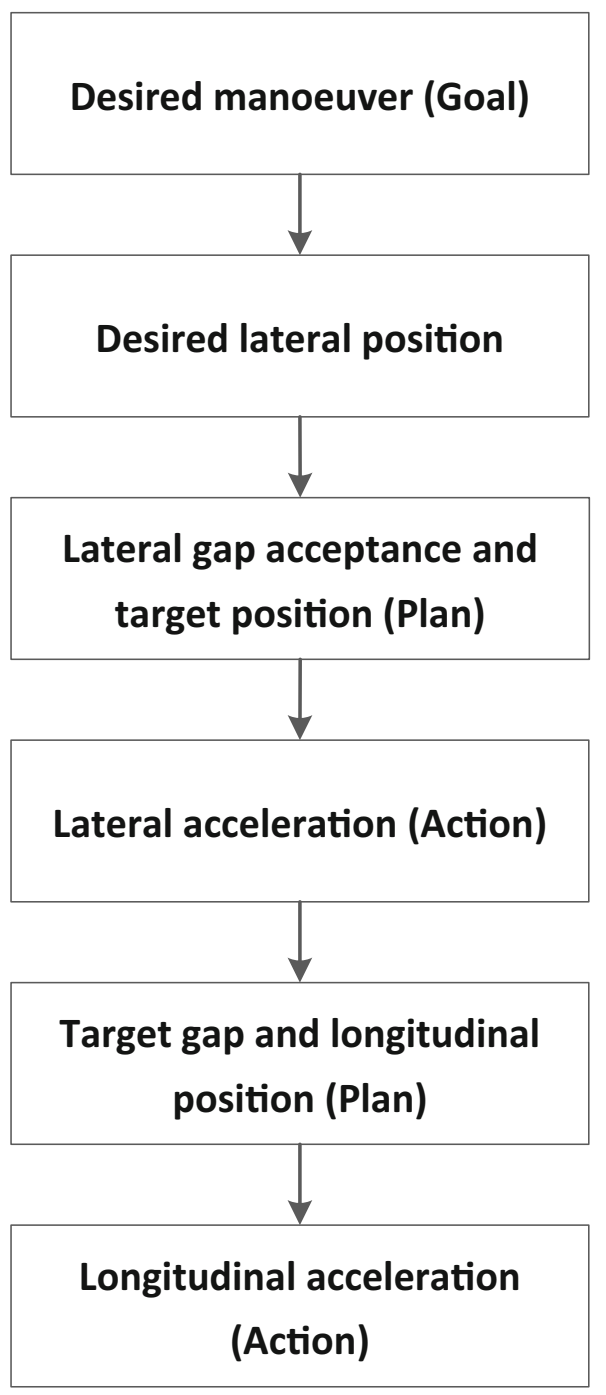

Fig. 11 Overall model framework for driver behavior in mixed traffic 
Fig. 12 Desired lateral positions
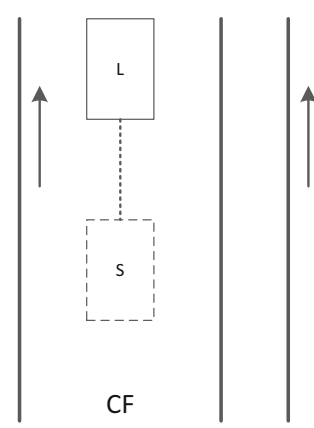
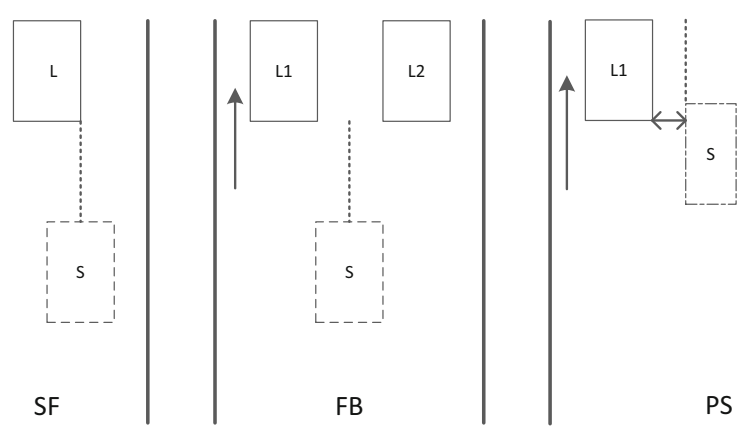

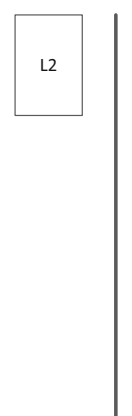

trajectories at a resolution of $0.5 \mathrm{~s}$ on a $200 \mathrm{~m}$ section in Chennai, India. In all these studies, the trajectory length is short due to the limited field of view of the cameras. Observations on longer sections are necessary in order to model complex behaviors patterns.

\section{Modelling Framework Outline}

This section outlines an integrated model for driving behavior that captures both longitudinal and lateral movement of the vehicles under mixed traffic conditions. Figure 11 shows the overall framework. In the first step, the drivers' goal is defined in terms of a desired manoeuver. Based on the literature, types of desired manoeuvers that may be considered include Car following (CF), Staggered following (SF), Following between two vehicles (FB), and Passing (PS). Examples of these situations were shown above in Fig. 10. The choice among the various alternatives may be based on decision rules or discrete choice models, and affected by the neighboring vehicles and their relative locations and speeds, the path plan and the characteristics of the driver.

The chosen desired manoeuver dictates a desired lateral position, where the driver would like to position the vehicle in order to complete the desired manoeuver. Figure 12 shows possible desired lateral positions for various manoeuvers. In $\mathrm{CF}$ and $\mathrm{SF}$, the desired lateral position may be the centerline and the edge, respectively, of the intended lead vehicle. In FB, the desired lateral position may be the middle point between the two leaders. In PS, the desired lateral position may be one that maintains a minimum safe distance the subject vehicle and the closer leader.

In some cases, it may not be feasible for the driver to immediately move to the desired position due to the presence of other neighboring vehicles. Therefore, a target lateral position may be defined, which is the furthest the driver able to move in the direction of the desired position. This position may be determined by applying gap

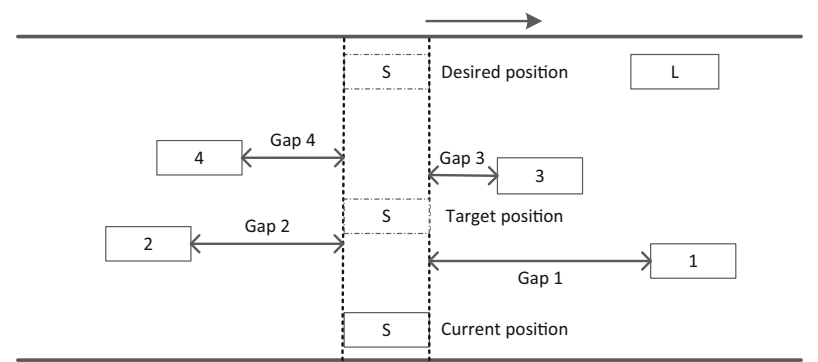

Fig. 13 Lateral gap acceptance and target position

acceptance functions on the available gaps in the direction of the desired lateral movement. This process is shown in Fig. 13. Suppose that the subject vehicle (S) decides to follow leader $(\mathrm{L})$, the desired lateral position is therefore directly behind the intended leader. The driver then evaluates the gaps with each one of the vehicles between its current and desired position from nearest to farthest (Gap 1 to Gap 4). The target position is dictated by the first gap to be rejected. For example, if gap 3 is rejected the target position would be dictated by the position of this vehicle and a safe lateral clearance. Gap acceptance decisions depend on the magnitude of the available gaps, the relative speed of the two vehicles, the types of vehicles and the urgency of the lateral movement.

For the lateral acceleration, as well as all other acceleration behaviors, it may be assumed that the driver reacts to different stimuli depending on the driving regime. For example, in lateral acceleration, the driver may react to the distance between the current position and the target position. In longitudinal acceleration, the driver may react to the leader relative speed in $\mathrm{CF}$ and $\mathrm{SF}$, the relative speeds of both leaders in FB and PS.

This framework outline allows to form integrated models for driving behavior that capture both longitudinal and lateral movement of vehicles and hence, inter-dependencies among them and different behaviors such as staggered following, vehicle following between two vehicles and passing. 


\section{Conclusions}

This paper reviews the state-of-the-art in driver behavior models under mixed traffic conditions: Longitudinal acceleration, lateral shift and gap acceptance models. Mixed traffic is characterized by a wide range of vehicle types and lack of lane discipline. As a result, there are driving behaviors that are specific to mixed traffic streams, such as staggered following, following between two vehicles, and passing and lateral shifts. There have been many attempts to model these behaviors separately. This paper outlines an integrated model framework for the two-dimensional movement of vehicles that has the potential to capture inter-dependencies in the movements. A major obstacle to development of mixed traffic driving models is the limited availability of trajectory data that is needed for estimation of their parameters.

Acknowledgments The second author was partly supported by a fellowship of the Israel Council for Higher Education at the Technion-Israel institute of Technology.

\section{References}

1. Annual Report (2013-2014) Ministry of Road Transport and Highways, Government of India, 2014

2. Ministry of Transport and Communication, China, 2014

3. Pucher J, Zeng ZR, Mittal N, Zhu Y, Korattyswaroopam N (2007) Urban transport trend and policies in China and India: impacts of rapid economic growth. Transp Rev 27(4):379-410

4. Singh SK (2012) Urban transport in India: issues, challenges and the way forward. Eur Transp 55:1-26

5. Hickman L (2010) Welcome to the worst traffic jam. The Guardian. http://www.guardian.co.uk/technology/2010/aug/23/ worlds-worst-traffic-jan. Accessed 5 Nov 2015

6. Sivak M and Schoettle B (2014) The University of Michigan Transportation Research Institute Ann Arbor, Michigan, USA

7. Ambient Air Pollution Database (2014) World Health Organization. http://www.who.int/phe/health_topics/outdoorair/databases/ cities/en/. Accessed 5 Nov 2015

8. Chakraborty A (2014) Effects of air pollution on public health: the case of vital traffic junctions under Kolkata Municipal Corporation. J Stud Dyn Change 1(3):125-133

9. Arasan VT, Koshy RZ (2005) Methodology for modeling highly heterogeneous traffic flow. J Transp Eng ASCE 131(7):544-551

10. Pipes LA (1953) An operational analysis of traffic dynamics. J Appl Phys 24(3):274-281

11. Brackstone M, McDonald M (1999) Car-following: a historical review. Transp Res Part F Traffic Psychol Behav 2(4):181-196

12. Toledo $\mathrm{T}$ (2007) Driving behaviour: models and challenges. Transp Rev 27(1):65-84

13. Chandler RE, Herman R, Montroll EW (1958) Traffic dynamics: studies in car following. Oper Res 6(2):165-184

14. Gazis DC, Herman R, Rothery RW (1961) Nonlinear follow the leader models of traffic flow. Oper Res 9:545-567

15. Gipps PG (1981) A behavioural car following model for computer simulation. Transp Res Part B 15(2):403-414

16. Krauss S (1997) Microscopic modeling of traffic flow: investigation of collision free vehicle dynamics. PhD Dissertation, University of Cologne
17. Treiber M, Hennecke A, Helbing D (2000) Congested traffic states in empirical observations and microscopic simulations. Phys Rev E 62(2):180S-1824

18. Leutzbach W, Wiedemann R (1986) Development and applications of traffic simulation models at the Karlsruhe Institut für Verkehrswesen. Traffic Eng Control 27(5):270-278

19. Bando M, Hasebe K, Nakayama A, Shibata A, Sugiyama Y (1995) Dynamical model of traffic congestion and numerical simulation. Phys Rev E 51(2):1035-1042

20. Chakroborty P, Kikuchi S (1999) Evaluation of the general motors based car-following models and a proposed fuzzy inference model. Transp Res Part C Emerg Technol 7(4):209-235

21. Lan LW, Chang CW (2004) Motorcycle-following models of general motors $(\mathrm{gm})$ and adaptive neuro-fuzzy inference system (in chinese). Transp Plan J 33(3):511-536

22. Chakroborty P, Agrawal S, Vasishtha K (2004) Microscopic modeling of driver behaviour in uninterrupted traffic flow. J Transp Eng ASCE 130(4):438-451

23. Latombe JC (1991) Robot motion planning. Kluwer Academic, Norwell

24. Minh CC, Sano K, Nguyen YC (2007) Acceleration and deceleration models of motorcycle at signalized intersections. J East Asia Soc Transp Stud 7:2396-2411

25. Ravishankar KVR, Mathew TV (2011) Vehicle-type dependent car-following model for heterogeneous traffic conditions. J Transp Eng ASCE 137(11):775-781

26. Cho HJ, Wu YT (2004) Modeling and simulation of motorcycle traffic flow. IEEE Int Conf Syst Man Cybernet 7:6262-6267

27. Lee TC, Polak JW, Bell MGH (2009) A new approach to modeling mixed traffic containing motorcycles in urban area. Transp Res Rec J Transp Res Board 2140:195-205

28. Jin S, Wang D, Xu C, Huang Z (2012) Staggered car-following induced by lateral separation effects in traffic flow. Phys Lett $A$ 376:153-157

29. Helbing D, Tilch B (1998) Generalized forced model of traffic dynamics. Phys Rev E 58(1):133

30. Gunay B (2007) Car following theory with lateral discomfort. Transp Res Part B 41:722-735

31. Sparmann U (1978) Spurwechselvorgänge auf ZweispurigenBABRichtungsfahrbahnen. ForschungStraßenbau und Straßenverkehrstechnik, Heft $\mathbf{2 6 3}$

32. Gipps PG (1986) A model for the structure of lane-changing decisions. Transp Res Part B Methodol 20(5):403-414

33. Hidas P, Behbahanizadeh K (1999) Microscopic simulation of lane changing under incident conditions. In: Proceedings of the 14th International Symposium on the Theory of Traffic Flow and Transportation, pp 53-69

34. Hidas P (2002) Modelling lane changing and merging in microscopic traffic simulation. Transp Res Part C 10:351-371

35. Wei H, Lee J, Li Q, Li CJ (2000) Observation-based lane-vehicleassignment hierarchy for microscopic simulation on an urban street network. In: Proceedings of the 79th TRB Annual Meeting, Washington DC, USA

36. Halati A, Lieu H, Walker S (1997) CORSIM-corridor traffic simulation model. In: Proceedings of the Traffic Congestion and Traffic Safety in the 21st Century Conference, pp 570-576

37. Yang QA (2007) Simulation laboratory for evaluation of dynamic traffic management systems. PhD Dissertation, Massachusetts Institute of Technology, USA

38. Ahmed KI (1999) Modeling drivers' acceleration and lane changing behavior. PhD Dissertation, Massachusetts Institute of Technology, USA

39. Toledo T (2003) Integrated driving behavior modeling, PhD Dissertation, Massachusetts Institute of Technology, USA 
40. Mallikarjuna C, Tharun B, Pal D (2013) Analysis of the lateral gap maintaining behaviour of vehicles in heterogeneous traffic stream. Procedia-Social Behav Sci 104:370-379

41. Luo Y, Jia B, Liu J, Lam HKW, Li X, Gao Z (2013) Modeling the interactions between car and bicycle in heterogeneous traffic. J Adv Transp. doi:10.1002/atr.1257

42. Oketch TG (2000) New modeling approach for mixed-traffic streams with non-motorized vehicles. Transp Res Rec 1705:61-69

43. Mathew TV, Munigety CR, Bajpai A (2013) Strip-based approach for the simulation of mixed traffic conditions. J Comput Civil Eng ASCE 29(5):04014069:1-9

44. Siddique MAB (2013) Modelling drivers' lateral movement behavior under weak-lane-disciplined traffic conditions. Thesis, Bangladesh University of Engineering and Technology, M. S

45. Munigety CR, Mantri S, Mathew TV, Krishna Rao KV (2014) Analysis and modelling of tactical decisions of vehicular lateral movement in mixed traffic environment. In: Proceedings of the TRB 93rd Annual Meeting, Washington DC, USA

46. Drew DR, LaMotte LR, Buhr JH, Wattleworth JA (1967) Gap acceptance in the freeway merging process. Highw Res Rec 208:1-36

47. Cohen E, Dearnaley J, Hansel CEM (1955) The risk taken in crossing a road. Op Res Quart 6:120-128

48. Solberg P, Oppenlander JD (1966) Lag and gap acceptance at a stop-controlled intersection. Highway Res Rec 118:48-67

49. Miller AJ (1972) Nine estimators of gap acceptance parameters. In: Proceedings of the 5th International Symposium on the Theory of Traffic Flow, pp 215-235

50. Daganzo CF (1981) Estimation of gap acceptance parameters within and across the population from direct roadside observation. Transp Res Part B 15:1-15

51. Mahmassani H, Sheffi Y (1981) Using gap sequences to estimate gap acceptance functions. Transp Res Part B 15:43-148

52. Madanat SM, Cassidy MJ, Wang MH (1994) A probabilistic model of queuing delay at stop controlled intersection approaches. J Transp Eng ASCE 120:21-36

53. Cassidy MJ, Madanat SM, Wang M, Yang F (1995) Unsignalized intersection capacity and level of service: revisiting critical gap. Transp Res Rec 1484:16-23

54. Choudhury CF, Ben-Akiva ME, Toledo T, Lee G and Rao A (2007) Modeling cooperative lane changing and forced merging behavior. In: Proceedings of the 86th Annual Meeting of the Transportation Research Board, Washington, DC, USA

55. Hidas P (2005) Modeling vehicle interactions in microscopic simulation of merging and weaving. Transp Res Part C Emerg Technol 13:37-62

56. Popat TL, Gupta AK, Khanna SK (1989) A simulation study of delays and queue lengths for uncontrolled T-intersections. Highw Res Bull Indian Road Congr 39:71-78

57. Raghavachari S, Badrinath KM, Bhanu Murthy PR (1993) Simulation of an urban uncontrolled urban intersection with pedestrian crossings. Highw Res Bull Indian Road Congr 48:29-49

58. Agarwal RK, Gupta AK, Jain SS (1994) Simulation of intersection flows for mixed traffic. Highw Res Bull Indian Road Congr 51:85-97

59. Kumar VM, Rao SK (1996) Simulation modeling of traffic operations on two-lane highways. Highw Res Bull Indian Road Congr 54:211-237

60. Sangole J, Patil GR, Patare P (2010) Modeling gap acceptance behavior of two-wheelers at uncontrolled intersections using neuro-fuzzy. Procedia-Social Behav Sci 20:927-941

61. Hossain M (1999) Capacity estimation of traffic circles under mixed traffic conditions using micro-simulation technique. Transp Res Part A 33:47-61
62. Pawar DS, Patil GR (2014) Temporal and spatial gap acceptance at uncontrolled intersections in India. Transportation Research Record, No. 2461, TRB, Washington DC, USA, pp 129-136

63. Ashalatha R, Chandra S (2011) Critical gap through clearing behavior of drivers at unsignalised intersections. KSCE Journal of Civil Engineering 15(8):1427-1434

64. Kanagaraj V, Srinivasan KK, Sivanandan R (2010) Modeling vehicular merging behavior under heterogeneous traffic conditions. Transp Res Rec 2188:140-147

65. Kanagaraj V, Srinivasan KK, Sivanandan R, Asaithambi G (2015) Study of unique merging behavior under mixed traffic conditions. Transp Res Part F Traffic Psychol Behav 29:98-112

66. Asaithambi G, Kanagaraj V, Srinivasan KK, Sivanandan R (2012) Characteristics on urban arterials with significant motorized two-wheeler volumes: role of composition, intra-class variability, and lack of lane discipline. Transp Res Rec 2317:51-59

67. Mathew TV, Ravi Shankar KVR (2011) Car-following behavior in traffic having mixed vehicle-types. Transp Lett Int $\mathrm{J}$ Transp Res 3(2):109-122

68. Kanagaraj V, Asaithambi G, Toledo T, Lee TC (2015) Trajectory data and flow characteristics of mixed traffic. Transp Res Rec 2491:1-11

69. Hurdle DI (1997) Motorcycling: time to apply the brakes. In: 25th European Transport Forum Annual Meeting: Policy, Planning and Sustainability, London pp 37-48

70. Wigan MR (2001) Motorcycles as transport. In: European Transport Conference, Association for European Transport, London, UK

71. Robertson SA (2002) Motorcycling and congestion: definition of behaviours. In: McCabe T (ed) Contemporary ergonomics. Taylor and Francis, London, pp 273-277

72. MRA (2006) Inquiry into managing transport congestion. Motorcycle Riders' Association of Australia. http:॥www. mraa. org.au/downloads/files/Congestion\%20paper\%20MRAA.pdf. Accessed 14 Nov 2015

73. Kanagaraj V, Asaithambi G, Sivanandan R (2008) Development of microscopic simulation model for heterogeneous traffic using object oriented approach. Transportmetrica 4(3):227-247

74. Asaithambi G, Kanagaraj V, Sivanandan R (2009) Object-oriented methodology for intersection simulation model under heterogeneous traffic conditions. Adv Eng Softw 40(10):1000-1010

75. Toledo T, Koutsopoulos HN, Ben-Akiva ME (2003) Modelling integrated lane-changing behaviour. Transp Res Rec 1857:30-38

76. Choudhury CF (2007) Modeling driving decisions with latent plans. PhD Dissertation, Department of Civil and Environmental Engineering, MIT

77. Mathew T, Radhakrishnan P (2010) Calibration of microsimulation models for non-lane based heterogeneous traffic at signalized intersections. J Urban Plann Dev 136:59-66

78. Sangole JP and Patil GR (2014) Modeling vehicle group gap acceptance at uncontrolled t-intersections in Indian traffic. In: Proceedings of the TRB $93^{\text {rd }}$ Annual Meeting, Washington DC, USA

79. Hidas $P$ and Wagner $P$ (2004) Review of data collection methods for microscopic traffic simulation. In: Proceedings of World Conference on Transport Research, Istanbul, Turkey

80. Slinn M, Guest P, Mathews P (1998) Traffic surveys. Traffic engineering design-principles and practice. Arnold, London, pp 6-26

81. Olsen ECB and Wierwille WW (2004) A unique approach for data analysis of naturalistic driver behavior data. SAE Future Transportation Technology Conference, Costa Mesa, CA

82. NGSIM-Next Generation SIMulation (2012) FHWA, US Department of Transportation. http://ops.fhwa.dot.gov/trafficana lysistools/ngsim.htm. Accessed 14 Nov 2015 
83. Kesting A, Treiber M (2008) Calibrating car-following models by using trajectory data: methodological study. Transp Res Rec 2088:148-156

84. Toledo T, Koutsopoulos HN, Ben-Akiva M (2009) Estimation of an integrated driving behavior model. Transp Res Part C 17(4):365-380

85. Moridpour S, Sarvi M, Rose G, Mazloumi E (2012) Lanechanging decision model for heavy vehicle drivers. J Intell Transp Syst Technol Plann Oper 16(1):24-35

86. Wan X, Jin P, Yang F and Ran B (2014) Modeling vehicle interactions during freeway ramp merging in congested weaving section. In: Proceedings of the 93rd TRB Annual Meeting, Washington, DC, USA

87. Marczak F, Daamen W, Buisson C (2013) Merging behaviour: empirical comparison between two sites and new theory development. Transp Res Part C Emerg Technol 36:530-546

88. Mallikarjuna C, Phanindra A, Rao KK (2009) Traffic data collection under mixed traffic conditions using video image processing. J Transp Eng ASCE 135(4):174-182 